\title{
FORMAÇÃO DE BIOFILMES EM TROCADORES DE CALOR E SEUS EFEITOS EM LEITE E DERIVADOS
}

\section{Biofilms formation in heat exchangers and its effects on milk and dairy products}

\author{
Elisângela Michele Miguel ${ }^{{ }^{*}}$, Antônio Fernandes de Carvalho ${ }^{2}$, Nélio José de Andrade $^{2}$,
} Ana Clarissa dos Santos Pires ${ }^{2}$, Junio Cesar Jacinto de Paula ${ }^{1}$, Renata Golin Bueno Costa ${ }^{I}$

\section{RESUMO}

A higienização ineficiente das superfícies de equipamentos tais como trocadores de calor têm como consequência o acúmulo de resíduos minerais que podem formar incrustações (fouling) de difícil remoção. Representam um dos maiores problemas para a operação de equipamentos, pois comprometem o seu desempenho e prejudicam o seu funcionamento, além de maior gasto com produtos químicos para ser realizado o processo de higienização. Além disso, devido à presença de resíduos minerais nas superfícies mal higienizadas, pode haver a adesão e a formação de biofilmes por microrganismos. Isso compromete a qualidade e vida de prateleira do leite e de seus derivados e pode colocar em risco a saúde do consumidor. Esta revisão bibliográfica tem como objetivo abordar os aspectos relevantes da formação de biofilmes em trocadores de calor, além do processo de formação de incrustações e os seus aspectos negativos para a indústria laticinista.

Palavras-chave: microrganismos; adesão; higienização; incrustações.

\begin{abstract}
The inefficient surface cleaning of equipments such as heat exchangers results in the accumulation of mineral residue that can form fouling which are difficult to

1 Empresa de Pesquisa Agropecuária de Minas Gerais, Instituto de Laticínios Cândido Tostes (EPAMIG/ ILCT). Rua Tenente de Freitas, 116, Santa Terezinha, 36560-000, Juiz de Fora, MG, Brasil. E-mail: elisangelamichele@epamig.br.

2 Universidade Federal de Viçosa (UFV), Departamento de Tecnologia de Alimentos, Viçosa, Minas Gerais, Brasil.

* Autor para correspondência
\end{abstract}

Recebido / Received: 21/08/2013

Aprovado / Approved: 06/11/2013 
remove. It can represent one of the biggest problems for the equipment operation decreasing its efficiency and impairing the functioning which can either involve greater spending on chemicals to be carried out the cleaning process. Moreover, due to the presence of mineral in poorly sanitized surface, there may be the adhesion and biofilm formation by microorganisms which can compromises the quality and the shelf-life of milk and dairy products and can bring risks to the consumer health. This review aims to address relevant aspects of biofilm formation in heat exchangers surfaces, the process of fouling and its negative aspects for the dairy industry.

Keywords: microorganisms; adhesion; surface cleaning; fouling.

\section{INTRODUÇÃO}

O leite, por sua riqueza em nutrientes, constitui-se em excelente substrato para o desenvolvimento de uma grande diversidade de microrganismos. Quando é obtido ou processado em condições higiênicas não satisfatórias, o leite pode veicular microrganismos patogênicos. Além disso, pode propiciar a multiplicação de deterioradores que diminuem a sua qualidade e a sua vida de prateleira e, consequentemente, de seus derivados.

O resfriamento do leite na fazenda e o seu transporte a granel são importantes instrumentos que visam à diminuição da multiplicação de bactérias mesófilas que provocam a acidificação desse produto. Entretanto, baixas temperaturas favorecem o desenvolvimento de microrganismos psicrotróficos os quais são capazes de se multiplicar em temperatura de refrigeração, independentemente da sua temperatura ótima de crescimento. Esses microrganismos psicrotróficos podem produzir enzimas proteolíticas e lipolíticas termoestáveis as quais provocam alterações indesejáveis no leite e seus derivados. Essas alterações comprometem a qualidade e, consequentemente, causam prejuízos para a indústria laticinista (NÖRBERG et al., 2010; MAZIERO et al., 2010).

$\mathrm{O}$ número de bactérias psicrotróficas presentes no leite cru está diretamente rela- cionado às condições higiênicas na produção. A contaminação pode originar-se da água de qualidade inadequada, deficiências de procedimento de higiene, além do tempo e a temperatura em que o leite é armazenado na propriedade rural e no estabelecimento processador. Uma contagem baixa dos microrganismos psicrotróficos é de fundamental importância para a qualidade do leite e de seus derivados. A atividade metabólica desses microrganismos pode resultar em alterações bioquímicas nos constituintes do leite que limitam a vida de prateleira dos produtos lácteos (ARCURI et al., 2008; NÖRBERG et al., 2009).

A qualidade de todos os produtos derivados do leite dependerá, basicamente, das condições microbiológicas da matéria-prima e também das condições de processamento e boas práticas em todas as etapas da industrialização. Uma vez que o leite contaminado entra em contato com as superfícies usadas durante o processamento e estocagem, as bactérias psicrotróficas podem se aderir nessas superfícies e tornarem-se fontes de recontaminação para as fabricações futuras (OULAHAL et al., 2008; NÖRBERG et al., 2011; CAIXETA et al., 2012). Portanto, os equipamentos utilizados durante a manipulação, o transporte, o processamento e o armazenamento constituem as principais fontes de recontaminação nas linhas de processamento do leite (FLACH et al., 2005; SIMÕES et al., 2010; SANTOS et al., 
2011a). A contagem bacteriana total do leite pode aumentar significativamente quando ocorre o contato com equipamentos nos quais a limpeza e sanitização são deficientes, pois os microrganismos proliferam nos resíduos presentes em recipientes onde pode ocorrer o seu acúmulo (FLACH et al., 2005; KASNOWSKI et al., 2010; SIMÕES et al., 2010; SANTOS et al., 2011). Na linha de produção da indústria laticinista, a formação de biofilmes eleva a carga microbiana dos produtos durante o processamento e, muitas vezes, os contamina com patógenos devido ao eventual desprendimento de células anteriormente aderidas. Desta forma, podem colocar em risco a saúde do consumidor, além de ocasionar prejuízos financeiros à indústria em decorrência da diminuição da vida de prateleira dos produtos (SANTOS; PEREIRA, 2009; SIMÕES et al., 2010; SANTOS et al., 2011b).

A adesão de bactérias patogênicas e deterioradoras, incluindo as bactérias psicrotróficas produtoras de enzimas termorresistentes, em superfícies sólidas com a conseqüente formação de biofilmes, constituem uma das preocupações atuais na indústria de laticínios. Isso é devido à potencialidade das bactérias em resistir a tratamentos antimicrobianos e à ação de diversos sanitizantes utilizados no processo de higienização (KASNOWSKI et al., 2010; TOYOFUKU et al., 2012), além de causar deterioração e perda de qualidade ou possibilidade de veicular patógenos (FLACH et al., 2005; OULAHAL et al., 2008; KASNOWSKI et al., 2010; NÖRBERG et al., 2011).

As bactérias do gênero Pseudomonas são encontradas com maior freqüência no leite e em derivados mantidos sob refrigeração e constituem a principal microbiota envolvida na produção de enzimas termorresistentes no leite (NÖRBERG et al., 2010; CAIXETA et al., 2012). Esse gênero é conhecido por secretar proteases extracelulares resistentes aos tratamentos de pasteurização e UHT (NÖRBERG et al., 2010; CHEN; CHEN, 2011).

A importância do controle da contaminação do gênero Pseudomonas na cadeia produtiva do leite é relacionada ao seu potencial enzimático que pode variar em função da estirpe (MARCHAND et al., 2009). Pseudomonas apresentam alta diversidade genética (MARTINS et al., 2006), além de mecanismos fisiológicos de adaptação e multiplicação a baixas temperaturas. Além disso, esse gênero apresenta a capacidade de formar biofilmes nas superfícies de equipamentos e utensílios (ARCURI et al., 2008; NÖRBERG et al., 2011; CAIXETA et al., 2012; TOYOFUKU et al., 2012), assim como em trocadores de calor, comumente utilizados na indústria laticinista (SANTOS et al., 2011b). Portanto, esta revisão bibliográfica foi desenvolvida com intuito de abordar o processo de formação de biofilmes por bactérias, assim como as suas características de resistência a agentes químicos e o processo de corrosão dos equipamentos. Em seguida, tratou-se do processo de formação de incrustações em trocadores de calor com consequente comprometimento de seu desempenho, e aumento de gastos com produtos químicos. Alguns aspectos relevantes da formação de biofilmes por microrganismos psicrotróficos em trocadores de calor foram relatados enfatizando os aspectos negativos para o processamento do leite.

\section{REFERENCIAL TEÓRICO}

\section{O processo de adesão microbiana e formação de biofilmes}

A higienização na indústria tem como objetivo preservar e garantir a qualidade microbiológica dos alimentos, para a obtenção 
de produtos que não ofereçam riscos à saúde do consumidor. Procedimentos de higienização mal conduzidos podem gerar graves conseqüências como a transmissão de agentes causadores de doenças, prejuízos econômicos como perdas totais de lotes produzidos e interrupção de processos de produção (SIMÕES et al., 2010; SANTOS et al., 2011a). A adoção de tecnologias que objetivam promover uma higienização eficiente dos equipamentos é uma necessidade da indústria laticinista e um ponto crítico de qualidade higiênico-sanitária. Assim, para garantir e manter a qualidade do leite tornase necessário o monitoramento do processo de higienização para evitar a formação de biofilmes e instituir ações corretivas, quando necessário (SANTOS; OLIVEIRA, 2007).

Um dos problemas que enfrenta a indústria laticinista é a recontaminação do leite decorrente da formação de biofilmes em tanques de armazenamento e trocadores de calor. Para se evitar a formação de biofilmes na indústria é essencial o estabelecimento e a adequação das medidas de higiene e sanitização (KASNOWSKI et al., 2010; SANTOS et al., 2011a). Entretanto, as operações de higienização são freqüentemente negligenciadas ou realizadas de forma inadequada, o que pode levar ao depósito de microrganismos e à sua aderência, com conseqüente formação de biofilme (SIMÕES et al., 2010; SANTOS et al., 2011b).

A adesão microbiana pode ocorrer devido à deposição de microrganismos em uma superfície de contato onde se fixam e iniciam o seu desenvolvimento. Essa multiplicação celular dá origem a colônias e, quando a massa celular é suficiente para agregar nutrientes, resíduos e outros microrganismos, estabelece-se o biofilme (FLACH et al., 2005; BOARI et al., 2009; KASNOWSKI et al., 2010).

Os biofilmes são depósitos onde os microrganismos estão fortemente aderidos, de forma organizada a uma superfície, tratando-se de um ecossistema complexo e dinâmico. Após a adesão, as células começam a se multiplicar e nesse meio, podem estar envolvidas por uma matriz polimérica de natureza protéica ou polissacarídica, formada a partir de células microbianas (BOARI et al., 2009; KASNOWSKI et al., 2010; TREVORS, 2011; TOYOFUKU et al., 2012). Os biofilmes possuem caráter protetor aos microrganismos, tornando, assim, uma fonte resistente de contaminação à ação de agentes químicos e físicos, como sanitizantes empregados nos processos de higienização (SIMÕES et al., 2010; PARK et al., 2012). Assim, a formação do biofilme é uma estratégia de sobrevivência de microrganismos em um ambiente com condições adversas, o que provoca uma alteração fenotípica de células planctônicas (vida livre) para a forma séssil (aderidas) e envolve a expressão de genes específicos para este fim (TREVORS, 2011; PARK, et al., 2012; TOYOFUKU et al., 2012). Quando existem em biofilmes, elas podem ser dez a mil vezes mais resistentes aos efeitos de agentes químicos, como os sanitizantes usados por indústria processadora de alimentos. $\mathrm{O}$ aumento da resistência dos biofilmes tem dificultado a sua eliminação, o que representa um fator preponderante em surtos de doenças transmitidas por alimentos. Esses surtos são causados por microrganismos patogênicos (KASNOWSKI et al., 2010; SIMÕES et al., 2010; PARK, et al., 2012), assim como pela veiculação de psicrotróficos patogênicos.

A principal estratégia para prevenir a formação de biofilmes é a higienização aplicada regularmente antes que a bactéria inicie o processo de adesão. Em estudos realizados por Park et al. (2012) foi observado que sanitizantes na forma de aerossóis apresentaram efeito significante contra biofilmes de patógenos de origem alimentar presentes nas linhas de processamento. Esta forma de aplicação pode efetivamente evitar 
a contaminação microbiana, pois é possível aplicar os sanitizantes em áreas do ambiente de difícil acesso, que são difíceis de serem higienizadas e, assim, controlar a formação de biofilmes. O controle é importante tendo em vista que a sua eliminação na planta de processamento é um desafio que exige medidas efetivas para minimizar esse problema (SIMÕES et al., 2010). O uso apropriado de sanitizantes físicos e químicos no equipamento industrial é importante para manter a qualidade do alimento e pode prevenir a formação do biofilme e/ou reduzir a contaminação. Entretanto, uma vez que a eliminação dos biofilmes das superfícies é uma tarefa difícil, o processo de higienização precisa ser analisado como um todo a fim de se aperfeiçoar os resultados e minimizar os custos de produção (CAIXETA et al., 2012).

\section{Fatores de resistência do biofilme}

Os biofilmes microbianos são extremamente resistentes a biocidas devido a fatores estruturais e fisiológicos. A matriz do biofilme é o fator mais importante de resistência estrutural. Dessa forma, um dos grandes responsáveis por conferir esta proteção seria a rede de exopolissacarídeo (EPS) formadas pelas bactérias presentes no biofilme (BOARI et al., 2009; TREVORS et al., 2011; PARK et al., 2012; TOYOFUKU et al., 2012) que age como barreira física, impedindo que os agentes sanitizantes cheguem aos sítios de ação nos microrganismos (BOARI et al., 2009; TREVORS et al., 2011; PARK, et al., 2012). O EPS também é capaz de adsorver cátions, metais e toxinas e conferir proteção contra radiações UV, alterações de $\mathrm{pH}$, choques osmóticos e dessecação (BOARI et al., 2009).

Segundo Mansfeld (2007) os microorganismos residentes em biofilmes protegem-se também dos efeitos tóxicos dos biocidas uma vez que esses são inativados pela ação de enzimas e ação de outros metabólitos que degradam ou neutralizam os agentes sanitizantes. Isso acarreta uma redução da quantidade de biocida disponível para atuar nos microrganismos. Outro aspecto negativo relacionado com os biofilmes é a corrosão de equipamentos e redução da capacidade da troca de calor entre as superfícies (MANSFELD, 2007; SANTOS; OLIVEIRA, 2007; SANTOS; PEREIRA, 2009; SANTOS et al., 2011b). Devido a esses fatores agravantes, conhecer as condições que propiciem a formação de biofilmes e as suas fragilidades é fundamental para que estratégias de controle mais econômicas e eficazes sejam dimensionadas para a eliminação de mais esta possibilidade de contaminação microbiana na indústria de alimentos (SIMÕES et al., 2010).

Estudos realizados por Simões et al. (2009) com espécies psicrotróficas de Pseudomonas e Bacillus cereus mostraram que as espécies associadas em biofilmes aumentam significativamente a resistência a tratamentos químicos e mecânicos testados, por apresentarem maior atividade metabólica e maior produção de EPS do que quando avaliadas separadamente. Este fenômeno pode ser atribuído à densidade de células. Além disso, a comunicação célula a célula (quorum sensing) desempenha papel importante na ligação entre essas. O quorum sensing está envolvido na biossíntese de enzimas, no desenvolvimento de biofilmes e na síntese de EPS (SIMÕES et al., 2010). Este processo foi detectado em bactérias psicrotróficas proteolíticas isoladas do leite cru e pode desempenhar papel importante na deterioração deste produto e de seus derivados, assim como na capacidade de formar biofilme nas superfícies que entram em contato com o leite (PINTO et al., 2007). Em estudos conduzidos por CAIXETA et al. (2012) com espécies de Pseudomonas foi observada a capacidade de adesão e formação de biofilmes em aço inoxidável em temperaturas de refrigeração 
de $4^{\circ} \mathrm{C}$ e $7^{\circ} \mathrm{C}$, comumente empregadas no resfriamento do leite. Os autores ressaltaram que a capacidade desses microrganismos de produzir EPS facilita significativamente a formação dos biofilmes.

Em relação à Bacillus cereus, de acordo com estudos realizados por Padegar; Singh (2012) o estágio fisiológico da célula exerce influência determinante na formação de biofilme por este microrganismo; processo considerado por esses autores mais importante para a sua sobrevivência do que o fator de virulência. Como este microrganismo possui a capacidade de formar esporo, que apresenta elevada hidrofobicidade superficial, sua adesão e a formação de biofilme nas linhas de processamento na indústria laticinista podem ocorrer, com conseqüente contaminação do leite e de seus derivados (ARAÚJO et al., 2009).

Segundo Simões et al. (2010) novas técnicas devem ser desenvolvidas com o intuito de eliminar efetivamente os biofilmes das superfícies que entram em contato com os alimentos, pois segundo estes autores, os desinfetantes não penetram na matriz de EPS do biofilme. Um procedimento efetivo de limpeza deve quebrar ou dissolver a matriz do EPS associado com o biofilme para que o sanitizante tenha acesso e elimine as células (SIMÕES et al., 2006). Por isso, a seleção de sanitizantes usados na planta de processamento da indústria laticinista é importante e deve ser capaz de remover os resíduos dos alimentos que podem conter microrganismos e promover a sua multiplicação (SIMÕES et al., 2010; SANTOS et al., 2011b), pois a diversidade da comunidade bacteriana presente no biofilme pode afetar a eficiência da desinfecção (SIMÕES et al., 2009).

De acordo com Santos; Oliveira (2007), os resíduos orgânicos e minerais protegem os microrganismos da ação do sanitizantes e podem aumentar também o consumo deste, o que gera um impacto econômico considerável.
Por isso, o planejamento e a aplicação das técnicas de higienização devem ser realizados levando-se em consideração a individualidade de cada planta de processamento, bem como as características dos resíduos, da natureza das superfícies e do layout do processamento.

\section{Incrustações e biofilmes na indústria de laticínios}

A limpeza e higienização ineficientes das superfícies na linha de produção de laticínios têm como a conseqüência a precipitação dos resíduos minerais que formam incrustações (fouling) que são complexos e de difícil remoção (MANSFELD, 2007; SANTOS; PEREIRA, 2009; SANTOS et al. 2011a). A formação de incrustações nas superfícies dos trocadores de calor durante o processamento do leite constitui um dos problemas de maior importância com impacto negativo nos custos de operação desses equipamentos. Isso implica efetivamente no comprometimento do desempenho térmico, na sobrecarga de bombas, no desligamento periódico para limpeza (running time) e até mesmo na substituição destes trocadores, além de comprometer a qualidade do leite e de seus derivados (SANTOS; PEREIRA, 2009; SANTOS et al., 2011a).

Nos processos de tratamento térmico do leite ocorre a formação de depósitos incrustantes sobre as superfícies de troca térmica de equipamentos, os quais proporcionam um meio propício à adesão microbiana. Como conseqüência forma-se biofilmes que reduz sensivelmente a eficiência da higienização. Esses biofilmes provocam uma diminuição na ação de sanitizantes e na área de troca de calor, prejudicando o tratamento térmico, a eficiência do equipamento e, conseqüentemente, a qualidade microbiológica do leite (BANSAL et al., 2009; SANTOS; PEREIRA, 2009; SANTOS et al., 2011b). Esses depósitos promovem também aumento nos ciclos de limpeza e formação de pontos de corrosão 
(SANTOS; OLIVEIRA, 2007; SANTOS; PEREIRA, 2009). Os biofilmes microbianos também possuem a capacidade de promover a biodegradação, pois realizam a biocorrosão de superfícies metálicas (MANSFELD, 2007).

Os trocadores de calor a placas de aço inoxidável são amplamente utilizados na indústria de laticínios devido a seu excelente desempenho na transferência de calor, baixo gradiente de temperatura, alta turbulência e fácil manutenção (BANSAL; CHEN, 2006; MAHDI et al., 2009). Entretanto, estão propensos à formação de incrustações devido aos estreitos canais e pontos de contato entre as placas (BANSAL; CHEN, 2006). A formação e o acúmulo de incrustações dependem fundamentalmente da temperatura. Isso ocorre devido à transferência de massa do leite que está sendo processado para as superfícies de aquecimento do trocador de calor, em função da solubilidade das proteínas (MAHDI et al., 2009; SANTOS; PEREIRA, 2009; SANTOS et al., 2011b). Existe uma ligação direta entre incrustação e desnaturação das proteínas quando os fluidos derivados do leite são processados em equipamentos de troca térmica. A $\beta$-Lactoglobulina é a soroproteína mais sensível a este processo e torna-se precursor para a formação de depósitos (LEI et al., 2011; SANTOS et al., 2011b). O comportamento dessa proteína é determinante para a formação das incrustações. Em altas temperaturas, a $\beta$-Lactoglobulina sofre desnaturação irreversível, com conseqüente exposição de grupos hidrofóbicos, até que se torne insolúvel e forme agregados (MAHDI et al., 2009; LEI et al., 2011; SANTOS et al., 2011;).

Em estudos realizados por Mahdi et al. (2009) acerca da formação de incrustações de leite em trocadores de calor a placas, os autores observaram uma relação direta entre o aumento da temperatura e a taxa de agregação de proteína desnaturada. Essa relação foi substancialmente acompanhada pela redução no coeficiente de transferência de calor, o que acarreta em prejuízos para a indústria laticinista devido à perda de eficiência do equipamento.

O segundo componente do leite mais importante para a formação de incrustações são os minerais, sobretudo cálcio e fósforo. Isso ocorre em função da relação inversa de solubilidade que os minerais apresentam em função da temperatura (MAHDI et al., 2009; SANTOS; PEREIRA, 2009; LEI et al., 2011; SANTOS et al., 2011a).

Durante o processamento do leite, diversos fatores afetam a formação de incrustações nas superfícies dos trocadores de calor, como as condições de processamento (SANTOS; PEREIRA, 2009; SANTOS et al., 2011a), as características da superfície (BANSAL; CHEN, 2006; KANANEH et al., 2010), principalmente rugosidade, design do equipamento e tensão interfacial (ROSMANINHO et al., 2007; LEI et al., 2011). Além da composição (BANSAL et al., 2009) e qualidade microbiológica do leite, assim como a qualidade da água utilizada em todos os pontos da obtenção do leite até o seu processamento (SANTOS; PEREIRA, 2009; SANTOS et al., 2011a).

As superfícies de aço inox apresentam alta tensão interfacial, o que facilita a adesão (BANSAL; CHEN, 2006). Estudos realizados por Kananeh et al. (2010) mostraram que a adesão dos depósitos poderia ser reduzida pelo decréscimo da tensão interfacial com materiais que possuem baixa energia superficial, tais como os de nanotecnologia. Os nanorevestimentos, com efeito, anti-adesão (antifouling) reduzem o acúmulo dos depósitos na superfície das placas dos trocadores de calor e poderiam ser utilizados com o intuito de melhorar a qualidade do leite, e reduzir a intensidade da limpeza do equipamento. Esses autores avaliaram diversos revestimentos de superfície com baixa energia superficial e baixa rugosidade e observaram que houve 
baixa formação de incrustações. Isso poderia simplificar o processo de higienização, reduzir os requerimentos químicos e melhorar a qualidade do leite.

Rosmaninho et al. (2007) estudaram a influência das propriedades de aço inox no comportamento de incrustações durante o processamento de leite e reportaram que a modificação das características físico-químicas das superfícies exerce influência determinante no processo de formação desses depósitos. Os autores testaram o comportamento de formação de fouling em superfícies com diferentes íons e observaram menor adesão de esporos de Bacillus cereus nessas superfícies avaliadas. Outra característica importante da superfície é a sua rugosidade da superfície dos trocadores de calor, apresentando forte relação com a intensidade de incrustações formada (LEI et al., 2011).

A composição do leite também influencia a formação das incrustações, pois a variação sazonal desse produto exerce impacto na composição dos depósitos. Leite com maior conteúdo de proteínas, principalmente no final do período de lactação, apresentará maior quantidade de depósitos formada durante o tratamento térmico (BANSAL et al., 2009).

A qualidade microbiológica do leite é determinante para a formação das incrustações. Quando o leite apresenta altas contagens de microrganismos psicrotróficos, ocorre à síntese de proteases termorresistentes por esses microrganismos que atuam sobre as micelas de caseína. Isso reduz a sua estabilidade ao calor e contribui de forma efetiva para a formação das incrustações (SANTOS; PEREIRA, 2009; SANTOS et al., 2011b). Esse processo é decorrente de falhas nos procedimentos de limpeza e sanitização das unidades produtivas. Também ocorre devido à logística incorreta de captação, com um longo tempo de estocagem do leite até o momento de seu processamento (SANTOS; PEREIRA, 2009; SANTOS et al., 2011b). A qualidade adequada da água utilizada em todo o processo de higienização também é essencial para diminuir os gastos de produção e melhorar a qualidade do leite (SANTOS; PEREIRA, 2007; MAHDI et al., 2009). A dureza da água deve ser controlada, uma vez que índices elevados podem provocar incrustações, e propiciar a adesão de microrganismos (SANTOS; PEREIRA, 2007; FLORENTINO et al., 2011). A água pode ser o principal veículo de contaminação e de recontaminação nas linhas de processamento de leite (SANTOS; PEREIRA, 2007).

Outro aspecto fundamental para a formação de fouling é o gradiente de temperatura entre o leite e a superfície de aquecimento. Quanto maior a diferença de temperatura, mais rapidamente ocorrerá a insolubilização de proteínas e minerais. Por isso, essa diferença de temperatura deve ser constantemente avaliada para se evitar o superaquecimento da água (SANTOS; OLIVEIRA, 2007). Além destes fatores, a turbulência do trocador de calor é importante e deve ser alta. Se for baixa, maior será a formação das incrustações (SANTOS et al., 2011). A velocidade de circulação do leite (ou de soluções de higienização) também influencia diretamente na adesão bacteriana e pode favorecer a formação de biofilmes nas linhas de processamento (FIGUEIREDO et al., 2009; CAIXETA et al., 2012).

A formação e o acúmulo de incrustações em linhas de processamento de leite é um problema cotidiano enfrentado pela indústria laticinista. É fundamental conhecer os fatores que influenciam na intensidade de sua formação, de modo a desenvolver sistemas eficientes de higienização, capazes de promover a remoção e controle das incrustações, e permitir equipamentos e linhas em condições ideais de operação (SANTOS; PEREIRA, 2009). Por outro lado, a adesão e formação de biofilmes microbianos são indesejáveis nos trocadores de calor na indústria de laticínios. Os biofilmes podem diminuir a transferência de calor e o 
fluxo em tubulações, desencadear processos corrosivos e principalmente tornarem-se fontes de contaminação microbiana. Como consequência, podem causar malefícios à saúde do consumidor ou reduzir a vida de prateleira do leite e de seus derivados. Os biofilmes microbianos também são responsáveis por significantes perdas de eficiência de processos tecnológicos e danos aos equipamentos (MANSFELD, 2007; SANTOS; PEREIRA, 2009; SANTOS et al., 2011a).

A remoção destes resíduos deve ser realizada imediatamente após o término do uso de equipamentos com medidas para evitar a sua formação. A seleção adequada de detergentes e sanitizantes depende de sua eficácia, segurança e facilidade de remoção, especialmente relacionada à natureza corrosiva dos tratamentos químicos e efeitos sensoriais no produto final (SIMÕES et al., 2010). Tendo em vista que o fenômeno é inevitável, é preciso utilizar tecnologias e procedimentos capazes de minimizar o desenvolvimento das incrustações. Isso inclui práticas higiênicosanitárias na obtenção do leite, otimização da logística de captação e processamento do leite, com diminuição, ao máximo, do tempo de estocagem e refrigeração e do pré-aquecimento do leite antes do tratamento térmico (SANTOS et al., 2011a).

Assim como a formação de incrustações nos equipamentos, o controle microbiano durante o processamento do leite, bem como de microrganismos psicrotróficos, é fundamental para se alcançar produtos de vida de prateleira desejáveis e seguros do ponto de vista microbiológico (NÖRBERG et al., 2009). A prática mais eficiente para limitar a multiplicação microbiana inclui boas práticas de higiene na produção, uma execução racional da linha de processo e uso efetivo de produtos de limpeza e sanitização. Devido ao aumento da resistência de biofilmes aos processos convencionais de higienização, novos meios para este controle são constantemente procurados para minimizar os fatores ambientais nas linhas de processamento (SIMÕES et al., 2010). Os depósitos devem ser removidos pelos procedimentos de limpeza intensivos e regulares com o objetivo de atender às especificações de higiene e qualidade dos produtos lácteos (KANANEH et al., 2010). O planejamento e a aplicação das técnicas de higienização devem ser realizados levando-se em consideração a individualidade de cada planta de processamento. Os sistemas de higienização devem atuar de forma sinérgica com as tecnologias de processamento, de modo a garantir estabilidade microbiológica do leite em níveis aceitáveis ao longo de sua cadeia produtiva (SANTOS; OLIVEIRA, 2007).

\section{CONSIDERAÇÕES FINAIS}

A formação de biofilmes microbianos em superfícies de trocadores de calor é uma preocupação constante para a indústria laticinista. Os biofilmes elevam a carga microbiana do leite e de seus derivados durante o processamento e, muitas vezes contaminaos com patógenos. Consequentemente colocam em risco a saúde do consumidor e ocasionam prejuízos financeiros à indústria em decorrência da diminuição da vida de prateleira do leite e derivados lácteos. Dessa forma, as práticas mais eficientes para limitar a formação de biofilmes incluem boas práticas de higiene na produção e o uso efetivo de produtos de limpeza e desinfecção.

\section{REFERÊNCIAS}

ARAÚJO, E.A. et al. Hidrofobicidade de ribotipos de Bacillus cereus isolados de indústria de laticínios. Alimentos e Nutrição, v.20, n.3, p.491-497, 2009.

ARCURI, E.F. et al. Contagem, isolamento e caracterização de bactérias psicrotróficas contaminantes de leite cru refrigerado. Ciência Rural, v.38, n.8, p.2250-2255, 2008. 
BANSAL, B.; CHEN, X.D. A critical review of Milk fouling in heat exchanges. Comprehensive Reviews in Food Science and Food Safety, v.5, n.4, p.169-186, 2006.

BANSAL, B. et al. Effect of seasonal variation in milk composition on dairy fouling. In: Proceedings of International Conference on Heat Exchanger Fouling and Cleaning, 8., 2009, Shladming. Proceedings... Shladming, 2009. p. 165-167. Disponível em: $<$ http://heatexchangerfouling.com/papers/papers2009/23_Bansal_F. pdf>. Acesso em: 05 jan. 2012.

BOARI, C.A. et al. Formação de biofilme em aço inoxidável por Aeromonas hydrophila e Staphylococcus aureus usando leite e diferentes condições de cultivo. Ciência e Tecnologia de Alimentos, v.29, n.4, p.886-895, 2009.

CAIXETA, D. S. et al. Chemical sanitizers to control biofilms formed by two Pseudomonas species on stainless steel surface. Ciência e Tecnologia de Alimentos, v. 32, n. 1, p. 142-150, 2012.

CHEN, T.R., CHEN, Q.K.W. Pseudomonas ssp and Hafnia alvei growth in UHT milk at cold storage. Food Control, v.22, n. 5, p.697-701, 2011.

FIGUEIREDO, H.M. et al. Influência da velocidade de circulação do leite na adesão de Pseudomonas aeruginosa sobre aço inoxidável. Ciência e Tecnologia de Alimentos, v.29, n.3, p.469-473, 2009.

FLACH, J., KARNOPP, C., CORÇÃO, G. Biofilmes formados em matéria-prima em contato com leite: fatores de virulência envolvidos. Acta Scientiae Veterinariae, v.33, n.3, p. 291-296, 2005.

FLORENTINO, E.R., SANTOS, A., SOARES, R. Psicrotróficos em leite pasteurizado. Higiene Alimentar, v.25, n.192/193, p. 20-22, 2011.

KANANEH, A. B. et al. Reduction of milk fouling inside gasteked plate heat exchanger using nano-coatings. Food and Bioproducts Processing, v.88, n.4, p.349-356, 2010.

KASNOWSKI, M.C. et al. Formação de biofilmes na indústria de alimentos e métodos de validação de superfícies. Revista Científica Eletrônica de Medicina Veterinária, v.8, n.15, julho 2010. Disponível em: $<$ http://faef.revista. inf.br/imagens_arquivos/arquivos_destaque/ fxPTiYWerLkT9Si_2013-6-25-16-32-0.pdf> Acesso em: 05 jan. 2012.

LEI, C. et al. Experimental observation of surface morphology effect on crystallization fouling in plate heat exchangers. International Commications in Heat and Mass Transfer, v.38, n.1, p.25-30, 2011.

MANSFELD, F. The interaction of bacteria and metal surfaces. Electrochimica Acta, v.52, n.27, p.7670-7680, 2007.

MARCHAND, S. et al. Heterogeneity of heatresistant proteases from milk Pseudomonas species. International Journal of Food Microbiology, v.133, n.1, p.68-77, 2009.

MAHDI, Y., MOUHEB, A., OUFER, L. A dynamic model for milk fouling in a plate heat exchanger. Applied Mathematical Modelling, v. 33, n. 2, p. 648-662, 2009.

MARTINS, M.L. et al. Genetic diversity of Gram-negative, proteolytic, psycrotrophic bactéria isolated from refrogerated raw milk. International Journal of Food Microbiology, v.111, n.2, p.144-148, 2006.

MAZIERO, M. T., VIANA, C., BERSOT, L. $\mathrm{S}$. Microrganismos psicrotróficos lipolíticos em produtos lácteos durante o prazo comercial. Revista do Instituto de Laticínios Cândido Tostes, v.65, n.372, p.30-35, 2010.

NÖRBERG, M. F. B. L., TONDO, E. C., BRANDELLI, A. Bactérias psicrotróficas e atividade proteolítica no leite cru refrigerado. 
Acta Scientiae Veterinariae, v.37, n.2, p.157163, 2009.

NÖRBERG, M.F.B.L. et al. Proteolytic activity among psychrotrophic bacteria isolated from refrigerated raw milk. International Journal of Dairy Science, v.63, n.1, p.41-46, 2010.

NÖRBERG, M.F.B.L. et al. A psychrotrophic Burkholderia cepacia strain isolated from refrigerated raw milk showing proteolytic activity and adhesion to stainless steel. Journal of Dairy Research, Cambridge, v.78, n. 1, p.1-6, 2011.

OULAHAL, N. et al. Quantitative analysis of survival of Staphylococcus aureus or Listeria innocua on two types of surfaces: Polypropylene and stailess steel in contact with three different dairy products. Food Control, v.19, n.2, p.178-185, 2008.

PAGEDAR, A., SINGH, J. Influence of physiological cell stages on biofilm formation by Bacillus cereus of dairy origin. International Dairy Journal, v.23, n.1, p.30-35, 2012.

PARK, S.H. et al. Inactivation of biofilm cells of foodborne pathogen by aerosolized sanitizers. International Journal of Food Microbiology, v.154, n.3, p.130-134, 2012.

PINTO, W.M. et al. Detection of acylated homoserine lactones in gram-negative proteolytic psycrotrophic bacteria isolated from cooled raw milk. Food Control, v.18, n. 10, p.1322-1327, 2007.

ROSMANINHO, R. et al. Modified stailess steel surgaces targeted to reduce foulingEvaluation of fouling by milk components. Journal of Food Engineering, v.80, n.4, p.1176-1187, 2007.

SANTOS, A.L., OLIVEIRA, P.H. Operações de higienização na indústria de laticínios: aspectos determinantes para sua eficiência: uma revisão.
Revista do Instituto de Laticínios Cândido Tostes, n. 359, v.62, p.25-29, 2007.

SANTOS, A. L., PEREIRA, D. B. C. A formação de incrustações no processamento do leite. Aspectos Químicos e Tecnológicos. In: CONGRESSO NACIONAL DE LATICÍNIOS, 26., 2009, Juiz de Fora. Anais... Juiz de Fora: Epamig/ILCT, 2009. 1 CD-ROM.

SANTOS, A.L., PEREIRA, D.B.C., SARAIVA, C.B. A formação do Fouling e seus impactos no processamento e limpeza de indústrias de laticínios (Parte 1). Revista Leite e Derivados, n.125, p.54-65, março/abril 2011a.

SANTOS, A.L., PEREIRA, D.B.C., SARAIVA, C.B. A formação do Fouling e seus impactos no processamento e limpeza de indústrias de laticínios (Parte 2). Revista Leite e Derivados, n.126, p.80-84, maio/junho 2011b.

SIMÕES, M. et al. Control of flow-generated biofilms using surfactants-evidence of resistance and recovery. Food and Bioproducts Processing, v.84, n.4, p.338-345, 2006.

SIMÕES, M., SIMÕES, L.C., VIEIRA, M.J. Species association increases biofilm resistence to chemical and mechanical treatments. Water Research, v.43, n.1, p.229-237, 2009.

SIMÕES, M., SIMÕES, L.C., VIEIRA, M.J. A review of current and emergent biofilm control strategies. LWT- Food Science and Techonology, v.43, n.4, p.573-583, 2010.

TREVORS, J.T. Viable but non-culturable (VBNC) bacteria: gene expression in planktonic and biofilm cells. Journal of microbiological methods, v.86. n.3, p. 266-273, 2011.

TOYOFUKU, M. et al. Identification of Proteins Associated with the Pseudomonas aeruginosa biofilm extracellular matrix. Journal of Proteome Research, v.11, n.10, p. 4906-4915, 2012. 


\section{0 MILAINOX ${ }^{\circledast}$}

\section{A dose certa de tecnologia para sua indústria.}

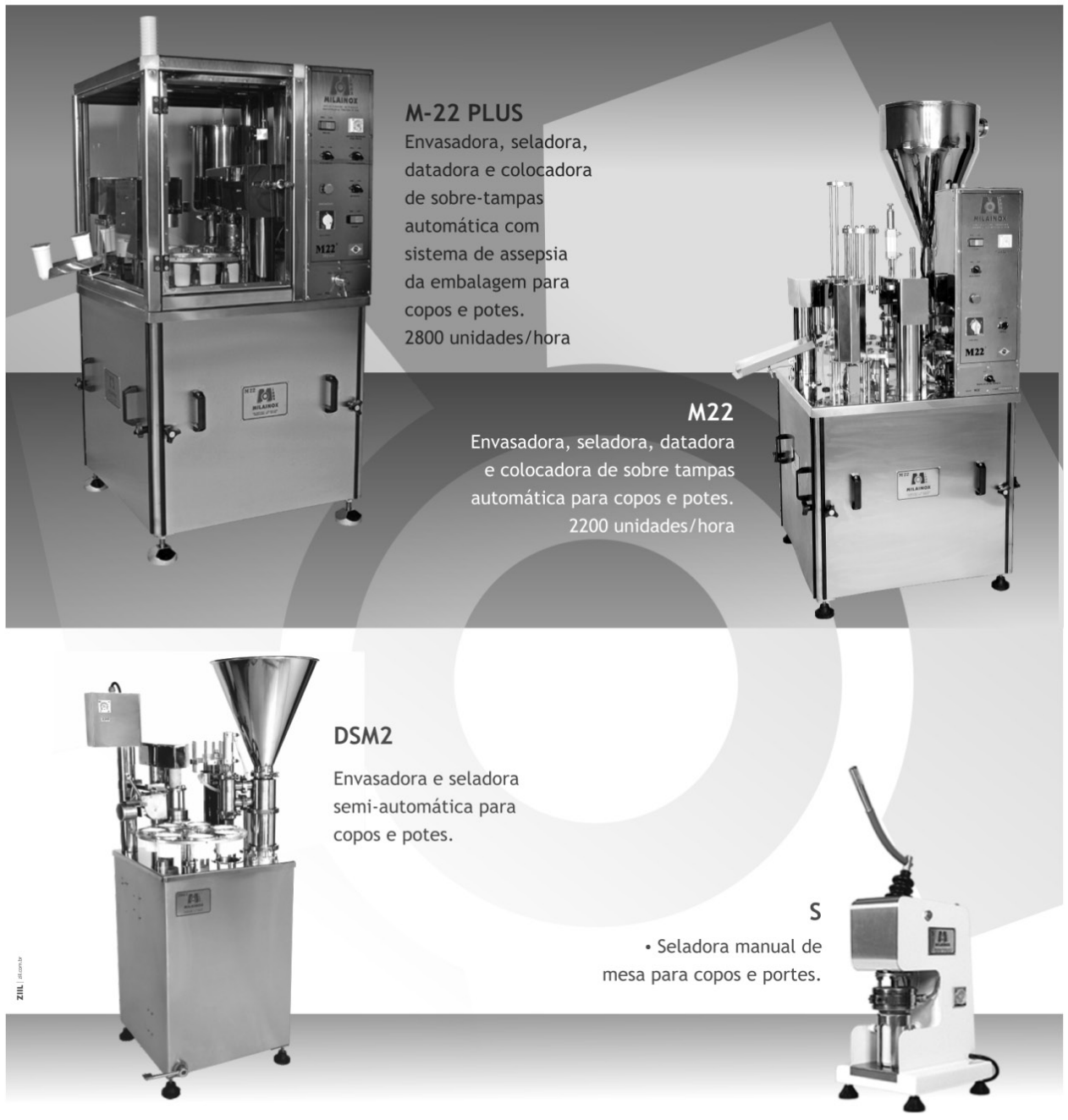

Piracicaba - SP - Brasil | (19) 3447-8950 / (19) 3422-3051 / (19) 3433-3051 / (19) 9756-7361 www.milainox.com.br /atendimento@milainox.com.br 